\title{
Growth of Cassia Siamea Lam in Semi- Arid Agroecosystems
}

\author{
Ramesh Chand Meena ${ }^{1}$, Ramavtar Sharma ${ }^{2}$ \\ ${ }^{1}$ PC Unit AICRP on Pearl Millet, ARS, Mandor, Agriculture University, Jodhpur - 342 304, India \\ ${ }^{2}$ Department of Botany, University of Rajasthan, Jaipur 302 004, India
}

\begin{abstract}
Cassia siamea Lam., a leguminous medicinal plant has become the first choice for green belt plantation program in urban cities. It is medium sized evergreen fast growing tree known to play major role in mitigating suspended particles. Growth study shows that initially plants grow very slow and attained height of $197.11 \pm 11.37 \mathrm{~cm}$ in three years. Research to increase growth rate of this ecofriendly plant is suggested.
\end{abstract}

Keywords: Cassia siamea, Ecological, Agroecosystems, Circumference, Diameter, central axis.

\section{Introduction}

Cassia siamea Lam. (Synonyms: Senna siamea, Cassia florida Vahl., Senna sumatrana Roxb. and Cassia arayatensis Naves) is a non nitrogenous fixing Leguminous tree sp. belonging to sub family Caesalpinoideae of the family Fabaceae / Leguminoseae cultivated all over the world (5). This plant plays an important ecological role as a biological factor in an ecosystem. It is used as wind break, shelter for controlling soil erosion and shade in tea/coffee plantations (4). Further, it increased the soil productivity due to the growth of herbs layers beneath its plantation (2). It is also used for restoration and rehabilitation of degraded lands and sodic waste lands (1). The present study was undertaken to investigate its growth rate after plantation for three successive years from July 2004 to June 2007.

\section{Material and Methods}

A number of 6 months old plants of $C$. siamea were planted in the soil in the botanical garden for monthly ecological observations for three years from July 2004 to June 2007. Each plant was planted at a distance of two meters from each other in two rows. Ten plants were selected for the plantation in an open field in the department of Botany for ecological observations. Selection was done on the basis of similar diameter, breadth and height $(\mathrm{DBH})$ of individual plants.

The following parameters were observed at monthly intervals for three years from July 2004 to June 2007.

1) Circumference

2) Total height of the plants from the surface of the soil to the top of the plant.

3) Diameter of the central axis.

4) The circumference and the diameter of the central axis were measured at three places just about the soil surface (DL), middle portion (DM) and the top (DU) of the planted trees of $C$. siamea. The planted trees were harvested after three years and biomass was taken after drying in sunlight (8).

\section{Result}

The results of growth of $C$. siamea trees planted in the botanical garden are summarized in Fig 1.

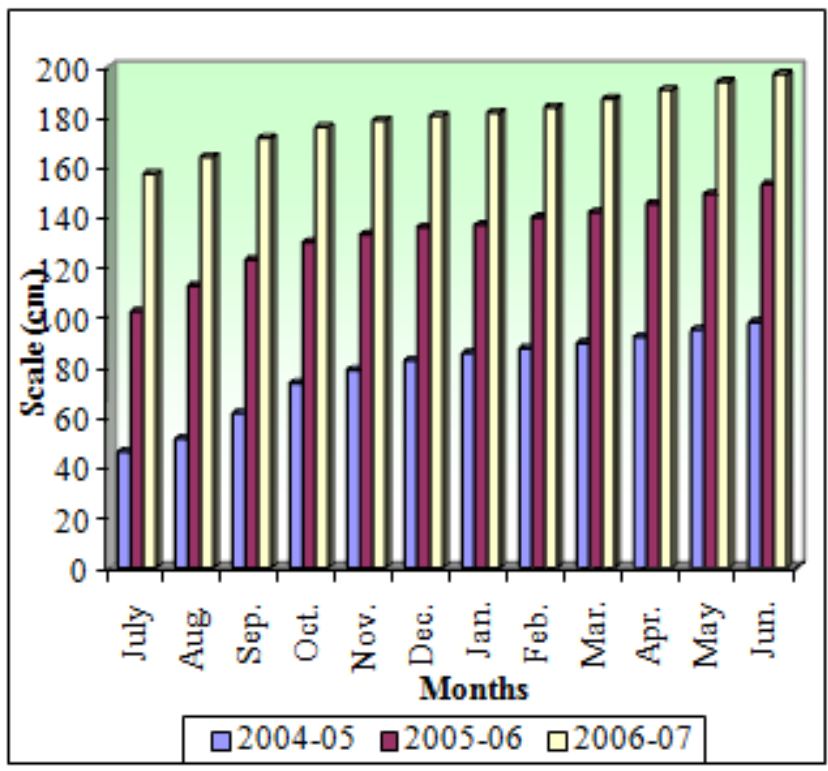

Figure 1: Mean height of planted C. siamea

It shows the mean height of planted trees of $C$. siamea in three respective years from 2004 to 2007 in the department of Botany. The maximum height of planted trees of $C$. siamea increased from $46.4 \pm 4.5$ to $98.01 \pm 6.27 \mathrm{~cm}$ in the $1^{\text {st }}$ year (2005), $153 \pm 7$ and $197.11 \pm 11.37 \mathrm{~cm}$ after $2^{\text {nd }}(2006)$ and $3^{\text {rd }}(2007)$ year of plantation. The diameter of lower portion of the planted trees (DL) increased from $1.0 \pm 0.15$ to $2.8 \pm 0.13 \mathrm{~cm}$ in $1^{\text {st }}$ year, $4.1 \pm 0.27 \mathrm{~cm}$ in the $2^{\text {nd }}$ year and $5.0 \pm$ $0.38 \mathrm{~cm}$ in the $3^{\text {rd }}$ year respectively. The middle diameter (DM) enhanced from $0.7 \pm 0.14$ to $2.2 \pm 0.22 \mathrm{~cm}$ in the $1^{\text {st }}$ year, $3.2 \pm 0.17$ in the $2^{\text {nd }}$ year and $3.9 \pm 0.17 \mathrm{~cm}$ in the $3^{\text {rd }}$ year, whereas the upper diameter (DU) enlarged from $0.5 \pm 0.19$ to $1.9 \pm 0.24 \mathrm{~cm}$ in $1^{\text {st }}$ year, $2.7 \pm 0.24$ in the $2^{\text {nd }}$ and $3.3 \pm 0.21 \mathrm{~cm}$ in the $3^{\text {rd }}$ year respectively (Table 1 ). 


\section{International Journal of Science and Research (IJSR) \\ ISSN (Online): 2319-7064}

Index Copernicus Value (2013): 6.14 | Impact Factor (2014): 5.611

Table 1: Mean diameter $(\mathrm{cm})$ of stem of planted trees of $C$. siamea $\mathrm{L}$

\begin{tabular}{|c|c|c|c|c|c|c|c|c|c|}
\hline & \multicolumn{3}{|c|}{$\mathbf{2 0 0 4 - 0 5}$} & \multicolumn{3}{c|}{ 2005-06 } & \multicolumn{3}{c|}{ 2006-07 } \\
\hline & DL & DM & DU & DL & DM & DU & DL & DM & DU \\
\hline July & $1.0 \pm 0.15$ & $0.7 \pm 0.14$ & $0.5 \pm 0.19$ & $2.9 \pm 0.15$ & $2.4 \pm 0.11$ & $2.0 \pm 0.20$ & $4.2 \pm 0.29$ & $3.3 \pm 0.12$ & $2.7 \pm 0.26$ \\
\hline Aug. & $1.3 \pm 1.30$ & $0.9 \pm 0.16$ & $0.7 \pm 0.14$ & $3.0 \pm 0.11$ & $2.5 \pm 0.14$ & $2.1 \pm 0.20$ & $4.2 \pm 0.29$ & $3.3 \pm 0.13$ & $2.7 \pm 0.27$ \\
\hline Sep. & $1.6 \pm 0.14$ & $1.1 \pm 0.20$ & $0.8 \pm 0.12$ & $3.2 \pm 0.11$ & $2.6 \pm 0.13$ & $2.2 \pm 0.20$ & $4.3 \pm 0.31$ & $3.4 \pm 0.41$ & $2.8 \pm 0.25$ \\
\hline Oct. & $1.7 \pm 0.11$ & $1.2 \pm 0.19$ & $0.9 \pm 0.19$ & $3.3 \pm 0.19$ & $2.7 \pm 0.15$ & $2.3 \pm 0.20$ & $4.4 \pm 0.34$ & $3.4 \pm 0.15$ & $2.9 \pm 0.24$ \\
\hline Nov. & $1.8 \pm 0.11$ & $1.3 \pm 0.24$ & $1.0 \pm 0.23$ & $3.4 \pm 0.13$ & $2.8 \pm 0.14$ & $2.3 \pm 0.18$ & $4.5 \pm 0.35$ & $3.5 \pm 0.36$ & $2.9 \pm 0.25$ \\
\hline Dec. & $2.0 \pm 0.11$ & $1.5 \pm 0.28$ & $1.1 \pm 0.27$ & $3.4 \pm 0.13$ & $2.8 \pm 0.16$ & $2.4 \pm 0.18$ & $4.6 \pm 0.36$ & $3.6 \pm 0.15$ & $2.9 \pm 0.26$ \\
\hline Jan. & $2.2 \pm 0.13$ & $1.6 \pm 0.28$ & $1.3 \pm 0.42$ & $3.5 \pm 0.13$ & $2.9 \pm 0.12$ & $2.4 \pm 0.20$ & $4.6 \pm 0.37$ & $3.6 \pm 0.12$ & $3.0 \pm 0.22$ \\
\hline Feb. & $2.3 \pm 0.12$ & $1.8 \pm 0.19$ & $1.4 \pm 0.20$ & $3.6 \pm 0.16$ & $3.0 \pm 0.11$ & $2.5 \pm 0.24$ & $4.6 \pm 0.37$ & $3.7 \pm 0.12$ & $3.0 \pm 0.23$ \\
\hline Mar. & $2.5 \pm 0.11$ & $2.0 \pm 0.13$ & $1.6 \pm 0.22$ & $3.7 \pm 0.20$ & $3.1 \pm 0.14$ & $2.5 \pm 0.17$ & $4.7 \pm 0.37$ & $3.7 \pm 0.14$ & $3.1 \pm 0.20$ \\
\hline Apr. & $2.6 \pm 0.09$ & $2.1 \pm 0.22$ & $1.8 \pm 0.30$ & $3.8 \pm 0.20$ & $3.1 \pm 0.12$ & $2.5 \pm 0.30$ & $4.8 \pm 0.14$ & $3.8 \pm 0.14$ & $3.1 \pm 0.23$ \\
\hline May & $2.7 \pm 0.11$ & $2.1 \pm 0.11$ & $1.9 \pm 0.23$ & $4.0 \pm 0.24$ & $3.2 \pm 0.10$ & $2.6 \pm 0.22$ & $4.9 \pm 0.40$ & $3.8 \pm 0.24$ & $3.2 \pm 0.20$ \\
\hline Jun. & $2.8 \pm 0.13$ & $2.2 \pm 0.22$ & $1.9 \pm 0.24$ & $4.1 \pm 0.27$ & $3.2 \pm 0.10$ & $2.7 \pm 0.24$ & $5.0 \pm 0.38$ & $3.9 \pm 0.17$ & $3.3 \pm 0.21$ \\
\hline
\end{tabular}

The breadth of lower portion of the planted trees (BL) enlarged from $0.5 \pm 0.14$ to $1.7 \pm 0.27 \mathrm{~cm}$ in $1^{\text {st }}$ year, $2.3 \pm 0.22$ $\mathrm{cm}$ in the $2^{\text {nd }}$ year and $2.7 \pm 0.33 \mathrm{~cm}$ in the $3^{\text {rd }}$ year respectively. The breadth of middle portion (BM) increased from $0.3 \pm 0.06$ to $1.5 \pm 0.15 \mathrm{~cm}$ in the $1^{\text {st }}$ year, $2.0 \pm 0.27$ in the $2^{\text {nd }}$ year and $2.4 \pm 0.26 \mathrm{~cm}$ in the $3^{\text {rd }}$ year, whereas the upper breadth (BU) increased from $0.2 \pm 0.3$ to $1.2 \pm 0.14 \mathrm{~cm}$ in $1^{\text {st }}$ year, $1.7 \pm 0.21$ in the $2^{\text {nd }}$ and $2.0 \pm 0.22 \mathrm{~cm}$ in the $3^{\text {rd }}$ year respectively (Table 2 ).

Table 2: Mean breadth $(\mathrm{cm})$ of stem of planted trees of $C$. siamea $\mathrm{L}$

\begin{tabular}{|c|c|c|c|c|c|c|c|c|c|}
\hline & \multicolumn{3}{|c|}{$\mathbf{2 0 0 4 - 0 5}$} & \multicolumn{3}{|c|}{$\mathbf{2 0 0 5 - 0 6}$} & \multicolumn{3}{|c|}{$\mathbf{2 0 0 6 - 0 7}$} \\
\hline & BL & $\mathbf{B M}$ & $\mathbf{B U}$ & $\mathbf{B L}$ & $\mathbf{B M}$ & $\mathbf{B U}$ & $\mathbf{B L}$ & BM & BU \\
\hline July & $0.5 \pm 0.14$ & $0.3 \pm 0.06$ & $0.2 \pm 0.30$ & $1.9 \pm 0.31$ & $1.5 \pm 0.15$ & $1.2 \pm 0.12$ & $2.4 \pm 0.20$ & $2.0 \pm 0.30$ & $1.7 \pm 0.24$ \\
\hline Aug. & $0.7 \pm 0.11$ & $0.4 \pm 0.17$ & $0.3 \pm 0.18$ & $1.9 \pm 0.36$ & $1.6 \pm 0.14$ & $1.3 \pm 0.11$ & $2.4 \pm 0.20$ & $2.0 \pm 0.30$ & $1.7 \pm 0.24$ \\
\hline Sep. & $0.8 \pm 0.09$ & $0.5 \pm 0.19$ & $0.3 \pm 0.20$ & $2.0 \pm 0.25$ & $1.7 \pm 0.17$ & $1.3 \pm 0.09$ & $2.5 \pm 0.22$ & $2.1 \pm 0.24$ & $1.8 \pm 0.22$ \\
\hline Oct. & $0.9 \pm 0.08$ & $0.5 \pm 0.21$ & $0.4 \pm 0.23$ & $2.0 \pm 0.23$ & $1.7 \pm 0.17$ & $1.4 \pm 0.11$ & $2.5 \pm 0.01$ & $2.1 \pm 0.23$ & $1.8 \pm 0.23$ \\
\hline Nov. & $1.0 \pm 0.11$ & $0.6 \pm 0.25$ & $0.5 \pm 0.23$ & $2.1 \pm 0.23$ & $1.8 \pm 0.17$ & $1.4 \pm 0.11$ & $2.5 \pm 0.22$ & $2.2 \pm 0.23$ & $1.8 \pm 0.23$ \\
\hline Dec. & $1.0 \pm 0.01$ & $0.7 \pm 0.22$ & $0.5 \pm 0.20$ & $2.1 \pm 0.23$ & $1.8 \pm 0.19$ & $1.5 \pm 0.11$ & $2.6 \pm 0.20$ & $2.2 \pm 0.25$ & $1.8 \pm 0.25$ \\
\hline Jan. & $1.2 \pm 0.09$ & $0.8 \pm 0.21$ & $0.6 \pm 0.24$ & $2.2 \pm 0.26$ & $1.8 \pm 0.21$ & $1.5 \pm 0.13$ & $2.6 \pm 0.21$ & $2.2 \pm 0.25$ & $1.9 \pm 0.23$ \\
\hline Feb. & $1.3 \pm 0.12$ & $0.9 \pm 0.13$ & $0.8 \pm 0.22$ & $2.2 \pm 0.25$ & $1.9 \pm 0.21$ & $1.5 \pm 0.15$ & $2.6 \pm 0.23$ & $2.3 \pm 0.23$ & $1.9 \pm 0.23$ \\
\hline Mar. & $1.4 \pm 0.12$ & $1.0 \pm 0.12$ & $0.9 \pm 0.18$ & $2.2 \pm 0.23$ & $1.9 \pm 0.21$ & $1.6 \pm 0.18$ & $2.6 \pm 0.21$ & $2.3 \pm 0.25$ & $2.0 \pm 0.25$ \\
\hline Apr. & $1.5 \pm 0.11$ & $1.1 \pm 0.14$ & $1.0 \pm 0.12$ & $2.3 \pm 0.20$ & $2.0 \pm 0.25$ & $1.6 \pm 0.18$ & $2.7 \pm 0.25$ & $2.3 \pm 0.23$ & $2.0 \pm 0.23$ \\
\hline May & $1.7 \pm 0.13$ & $1.3 \pm 0.15$ & $1.1 \pm 0.11$ & $2.3 \pm 0.21$ & $2.0 \pm 0.25$ & $1.6 \pm 0.19$ & $2.7 \pm 0.24$ & $2.3 \pm 0.26$ & $2.0 \pm 0.23$ \\
\hline Jun. & $1.7 \pm 0.27$ & $1.5 \pm 0.15$ & $1.2 \pm 0.14$ & $2.3 \pm 0.22$ & $2.0 \pm 0.27$ & $1.7 \pm 0.21$ & $2.7 \pm 0.33$ & $2.4 \pm 0.26$ & $2.0 \pm 0.22$ \\
\hline
\end{tabular}

$\mathrm{DL}=$ Diameter of lower $; \mathrm{DM}=$ Diameter of middle $; \mathrm{DU}=$ Diameter of upper portion of planted trees of $C$. siamea, $\pm \mathrm{SE}$

The growth rate of $C$. siamea is shown in Fig. 2. The average growth rate was estimated 56.61, 50.72 and 39.84 $\mathrm{cm}$ in $1^{\text {st }}, 2^{\text {nd }}$ and $3^{\text {rd }}$ year respectively. Flowering in planted trees of $C$. siamea was not initiated during the study period (2004-07).

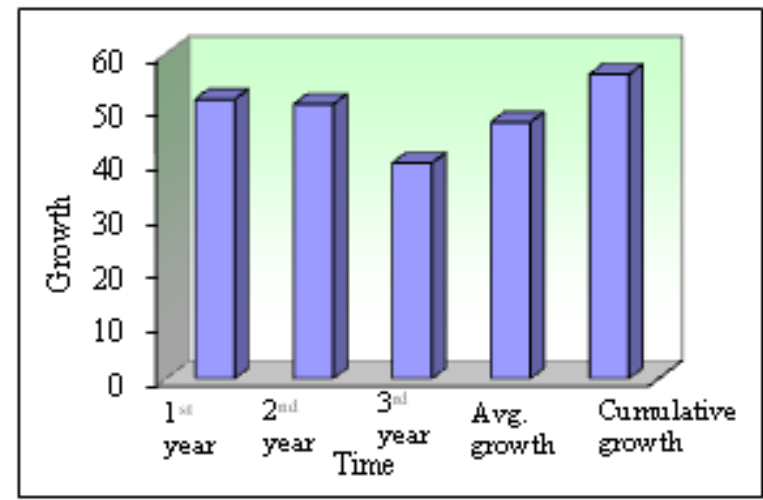

Figure 2: Growth of C. siamea in $1^{\text {st }}, 2^{\text {nd }}$ and $3^{\text {rd }}$ year of plantation
, $\mathrm{BL}=$ Breadth of lower $; \mathrm{BM}=$ Breadth of middle $; \mathrm{BU}=$ Breadth of upper portion of planted trees of $C$. siamea, $\pm \mathrm{SE}$

Growth = Hf-Hi/Time, Hf-final height (cm), hi-initial height, Time-3 years from 2004-2007

\section{Discussion}

C. siamea is the most suitable agroforestry tree with its good quality wood, and aesthetic value with great economic importance as a valuable important medicinal plant (7). Because of these qualities this plant fits well into the social forestry programmes of the government in which it aims to enlist the support of farmers in reforestation. Exotic invasive plants have attracted attention for land use systems throughout the world during recent years (McIntyre and Lovorel, 1994).

C. siamea has been planted in Jaipur under various programmes of social forestry from last few years. As a result, after plantation a green belt of $C$. siamea tree is flanked on either side of the major long roads and railway tracks in the city. This plant became the first choice because it is fast growing, evergreen, multipurpose, medicinal tree and it flowers throughout the year (3). The other reason may 
be its well adaptive nature to semi arid conditions; whereas other indigenous trees except desert species are difficult to plant particularly in the scarcity of water.

Cassia siamea trees are fast growing plants attaining height upto $30 \mathrm{~m}$ but the study shows that initial growth is rather very slow. The trees attained very little height in three years after being planted in the department of Botany for the present study.

\section{References}

[1] Agarwal, S., and Tiwari, S.L. (1997). Impact of air pollutants from steel kilns emission on some tree species. Vashundhara. 2: 77-79.

[2] Bhatt, D.M., Murali, K.S., and Ravindranath, N.H. (2002). Comparison of field performance of two exotic species: Acacia auricui iformis and Cassia siamea in hilly and high rain fall zone of Uttara Kannada district, Western Ghats, CES Technical Report No. 93 Centre for Ecological Sciences IIS, Bangalore.

[3] Carlowitz, V.P.G. (1991). Multipurpose trees and shrubs: sources of seed in inoculants. Nairobi, Kenya : International Council for Research in Agroforestry (ICRAF)

[4] Chaurasia, B., Mahagan, S., and Chauhan, S.V.S. (2002). Impact of automobile pollution on phenology and reproducition biology of Cassia siamea Lam. Indian J. Env. Sci. 6(1): 85-90.

[5] Gutteridge, R.C. (1997). Senna siamea (Larnk.). Irwin Bombey. pp. 232-236. In : H.I. Fariday, and L.J.G. Vander Maesen, (eds.). Plant Research of South-East Asia no. 11. Auxiliary Plants. Backhuys Publishers, Leiden, The Netherlands

[6] Mclntyre, S., and Lavorel (1994). Predicting richness of native, rare and exotic plants in response to habitat and disturbance variable across a variegated landscape. Conservation Biology, 8(2): 521-531.

[7] Meena, R.C., Darji, B. L., Saxena, M.K., Sharma, R.A. and Verma, P.K. (2012). Phenological Studies of a Medicinal Plant Cassia siamea. Current Research in Biological and Pharmaceutical Sciences. 1(2):10-12

[8] Rich, P.M. Helenurum, K., Kearns, D., Morse, S.R., Palmer, M.W. and Short, L. (1986). Height and stem diameter relationship for dicotyledonous trees and orborescent palms of Costa Rica Tropical Wet Forest. 113 (3): 241-246. 